\title{
A Case of Ticagrelor Resistance
}

\author{
$\underline{\text { Jahanzeb Malik }}$ \\ Rawalpindi Institute of Cardiology, Rawal Road, Rawalpindi, Punjab, Pakistan
}

Received: 15/06/2021

Accepted: $21 / 06 / 2021$

Published: $13 / 07 / 2021$

How to cite this article: Malik J. A case of ticagrelor resistance. EJCRIM 2021;8: doi:10.12890/2021_002719.

Conflicts of Interests: The authors declare there are no competing interests.

Ethics statement: This study was conducted according to the principles of the Declaration of Helsinki. The patient provided informed written consent for the publication of this report. Ethical approval was obtained prior to submission from the Research and Ethics Committee (ID\#RERC/20/DCA/51).

This article is licensed under a Commons Attribution Non-Commercial 4.0 License

\section{ABSTRACT}

Ticagrelor is a directly acting cyclopentyltriazolo-pyrimidine which does not require conversion into an active metabolite. It inhibits the $\mathrm{P}_{2} \mathrm{Y}_{12}$ receptors on platelets reversibly. Unlike clopidogrel and prasugrel, resistance to ticagrelor is rarely reported. Various mechanisms have been proposed for this resistance. The case of a 62-year-old man with diabetes who had undergone index percutaneous coronary intervention $(\mathrm{PCl}) 22$ days previously is described. The patient presented to us with stent thrombosis. His primary $\mathrm{PCl}$ was successfully carried out with a drug-eluting stent. He showed resistance to ticagrelor on thromboelastography platelet mapping. He responded well to prasugrel (another $\mathrm{P}_{2} \mathrm{Y}_{12}$ inhibitor) in combination with aspirin.

\section{LEARNING POINTS}

- $\quad$ Ticagrelor is a pro-drug and directly inhibits ${\mathrm{P} 2 \mathrm{Y}_{12}}_{12}$ receptors.

- This makes ticagrelor less susceptible to drug-drug interactions or pharmacogenetic influences.

- Thromboelastography platelet mapping measures the physical properties of clot formation and can reveals platelet resistance to various $\mathrm{P}_{2} \mathrm{Y}_{12}$ inhibitors, including ticagrelor.

\section{KEYWORDS}

Ticagrelor, coronary artery disease, stent thrombosis, dual anti-platelet therapy

\section{INTRODUCTION}

Platelet inhibition is pivotal to reduce cardiovascular events in patients with coronary artery disease. Aspirin is the cornerstone treatment, but in this era of dual anti-platelet therapy (DAPT), the addition of a P2Y ${ }_{12}$ inhibitor is recommended in acute coronary syndromes ${ }^{[1]}$. Large scale trials have seen a shift from clopidogrel to prasugrel for $\mathrm{P}_{2} \mathrm{Y}_{12}$ inhibition in patients with ST-elevation myocardial infarction (STEMI) and to ticagrelor in non-ST-elevation MI (NSTEMI) ${ }^{[2]}$. However, despite DAPT, some patients experience recurrent cardiovascular events. Apart from non-compliance, a lack of response to anti-platelet therapy has been documented in many studies.

A case of a sub-acute stent thrombosis (ST) in a patient after drug-eluting stent (DES) implantation and demonstrated resistance to ticagrelor on platelet mapping is described. 


\section{CASE DESCRIPTION}

A 62-year-old man with type 2 diabetes and previous inferior STEMI, was treated with DES in the right coronary artery. He presented with ST 22 days after his index primary percutaneous coronary intervention while on aspirin 75 mg once daily and ticagrelor 90 mg twice daily. He was successfully treated with plain old balloon angioplasty with a drug-eluting balloon (SeQuent Neo, B. Braun, Melsungen, Germany). The mechanism of ST was not known, so intravascular abnormality was assessed via optical coherence tomography. The stent was wellapproximated with no edge dissection or strut mal-apposition. History taking did not reveal any non-compliance with DAPT. The patient was haemodynamically stable after the procedure and his baseline haematology and biochemistry findings were within normal limits.

After consultation with a haematologist, a platelet mapping study was advised with thromboelastography platelet mapping (TEG) (Haemoscope Corporation, Niles, IL, USA), which showed resistance to ticagrelor with a maximum amplitude (MA) of 66 mm with ADP. After a 1-week hospital stay, the patient was discharged on aspirin $150 \mathrm{mg} /$ day and prasugrel $10 \mathrm{mg} / \mathrm{day}$.

\section{DISCUSSION}

A number of studies have explained the reasons for platelet reactivity to clopidogrel, and include various genetic polymorphisms, hyporeactivity and drug interactions ${ }^{[3]}$. However, little information is available on the causes of ticagrelor resistance. Ticagrelor is a pro-drug and directly inhibits P2Y12 receptors. This makes it less susceptible to drug-drug interactions or pharmacogenetic influences.

A large-scale trial implicated a reduced effect of ticagrelor when given in combination with morphine, but the results were not statistically significant ${ }^{[4]}$. Similarly, smoking is also proposed as a substrate for increased platelet reactivity. The Platelet Inhibition and Patient Outcomes (PLATO) trial demonstrated the rate of ST with ticagrelor was $2.94 \%{ }^{[5]}$. It was seen that ticagrelor decreased sub-acute (24 h to $30 \mathrm{days)}$ and late (>30 days) ST. However, the ST was not sub-acute in our case.

We used TEG to look for $\mathrm{P}_{2} \mathrm{Y}_{12}$ resistance. It measures the physical properties of clot formation. The MA demonstrates the clot strength which can test the effectiveness of $\mathrm{P}_{2} \mathrm{Y}_{12}$ inhibitors and aspirin by platelet activation with ADP. A study found that an MA of $>47 \mathrm{~mm}$ was a strong predictor of platelet resistance and adverse events after coronary stenting ${ }^{[6]}$.

\section{CONCLUSION}

The prevalence of platelet resistance is greater with clopidogrel therapy as compared with ticagrelor or prasugrel. The differences are likely due to a different array of pharmacokinetics where ticagrelor produces effective platelet inhibition compared with clopidogrel. However, drug resistance is present in rare instances and TEG can play a pivotal role in detecting hypo-responsiveness. Changing to a more potent $\mathrm{P}_{2} \mathrm{Y}_{12}$ inhibitor is the treatment of choice for ticagrelor resistance.

\section{REFERENCES}

1. Lee OH, Kim BK, Hong SJ, Kim S, Ahn CM, Shin DH, et al. Determinants and clinical outcomes of extended dual antiplatelet therapy over 3 years after drug-eluting stent implantation: a retrospective analysis. Yonsei Med J 2020;61(7):597-605. doi: 10.3349/ymj.2020.61.7.597. PMID: 32608203; PMCID: PMC7329747.

2. Sucato V, Corrado E, Castellana C, Carella M, Raso S, Coppola G, et al. Real-world use of ticagrelor and prasugrel in patients with NSTEMI undergoing percutaneous coronary intervention. J Cardiovasc Med (Hagerstown) 2017;18(6):450-451. doi: 10.2459/JCM.0000000000000516. PMID: 28306694.

3. Liu Z, Tian R, Wang Y, Chen Q, Li J, Xu L, et al. Platelet inhibition with ticagrelor versus clopidogrel in diabetic patients after percutaneous coronary intervention for chronic coronary syndromes. Thromb Haemost 2020;120(8):1221-1229. doi: 10.1055/s-0040-1713375. PMID: 32668483.

4. Kubica J, Adamski P, Ostrowska M, Koziński M, Obońska K, Laskowska E, et al. Influence of Morphine on Pharmacokinetics and Pharmacodynamics of Ticagrelor in Patients with Acute Myocardial Infarction (IMPRESSION): study protocol for a randomized controlled trial. Trials 2015;16:198. doi: 10.1186/s13063-015-0724-z. PMID: 25925591; PMCID: PMC4424595.

5. Pollack CV Jr, Davoudi F, Diercks DB, Becker RC, James SK, Lim ST, et al; PLATO Investigators. Relative efficacy and safety of ticagelor vs clopidogrel as a function of time to invasive management in non-ST-segment elevation acute coronary syndrome in the PLATO trial. Clin Cardiol 2017;40(6):390-398. doi: 10.1002/clc.22733. PMID: 28598510; PMCID: PMC6490557.

6. Cheng D, Zhao S, Hao Y. Net platelet clot strength of thromboelastography platelet mapping assay for the identification of high on-treatment platelet reactivity in post-PC patients. Biosci Rep 2020;40(7):BSR20201346. doi: 10.1042/BSR20201346. PMID: 32639536; PMCID: PMC7364512. 